\title{
Sleep habits and biological clocks determined in children: cognitive fluctuations and intelligence.
}

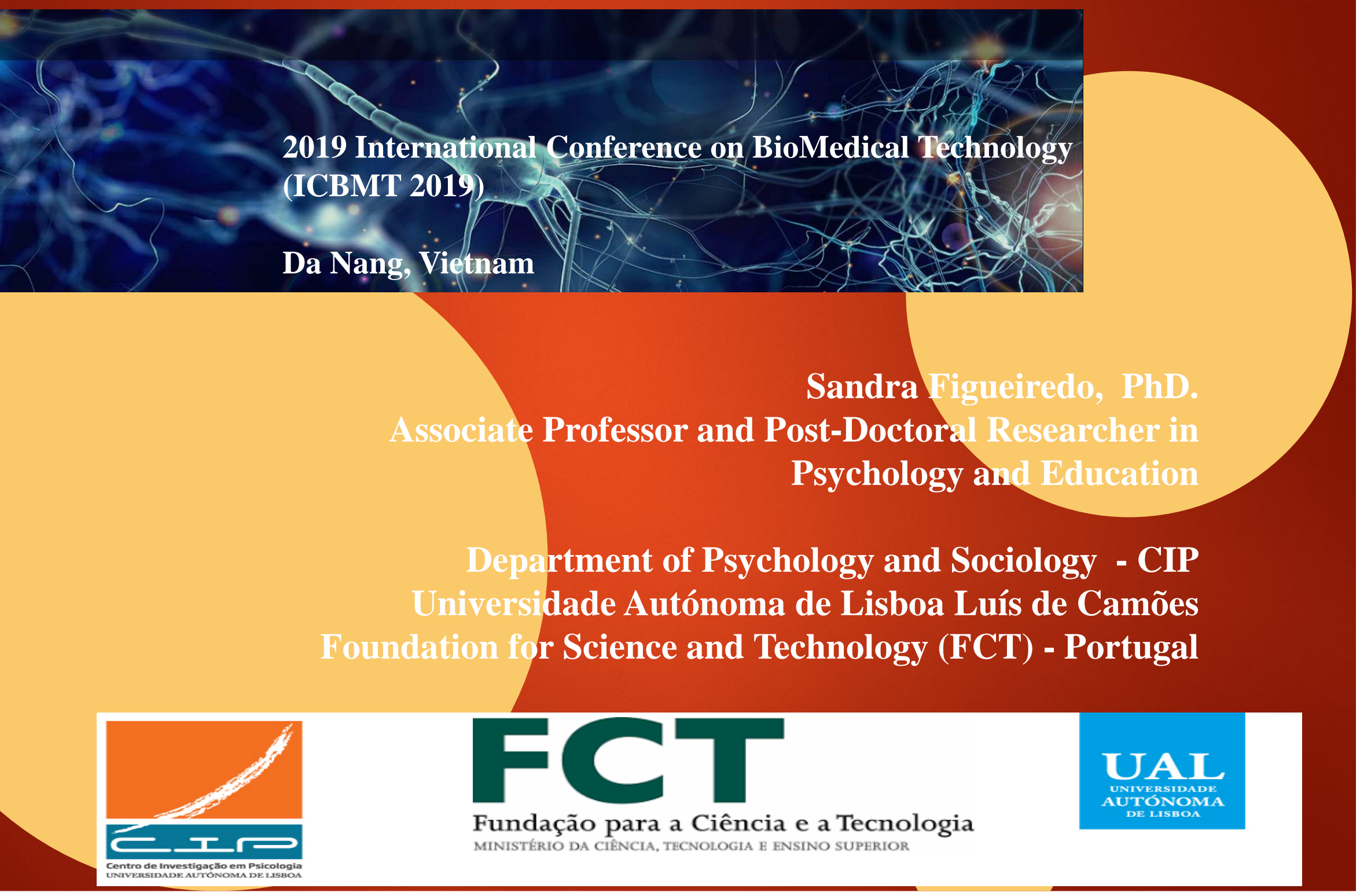




\section{Diurnal type, intelligence and}

achievement in Grammar Schoo dren

- chronobiology area

Evidence shows: Due to scant published literature, it is still not possible to completely understand how cognition (and academic implications) would be enhanced through the adjustment of timetables for classes and evaluations, nor to select the most appropriate schedules for study and other activities.

To examine: chronotype' significant influence for the cognitive performance of children aged between 7 and eleven years old - the attention skills. 


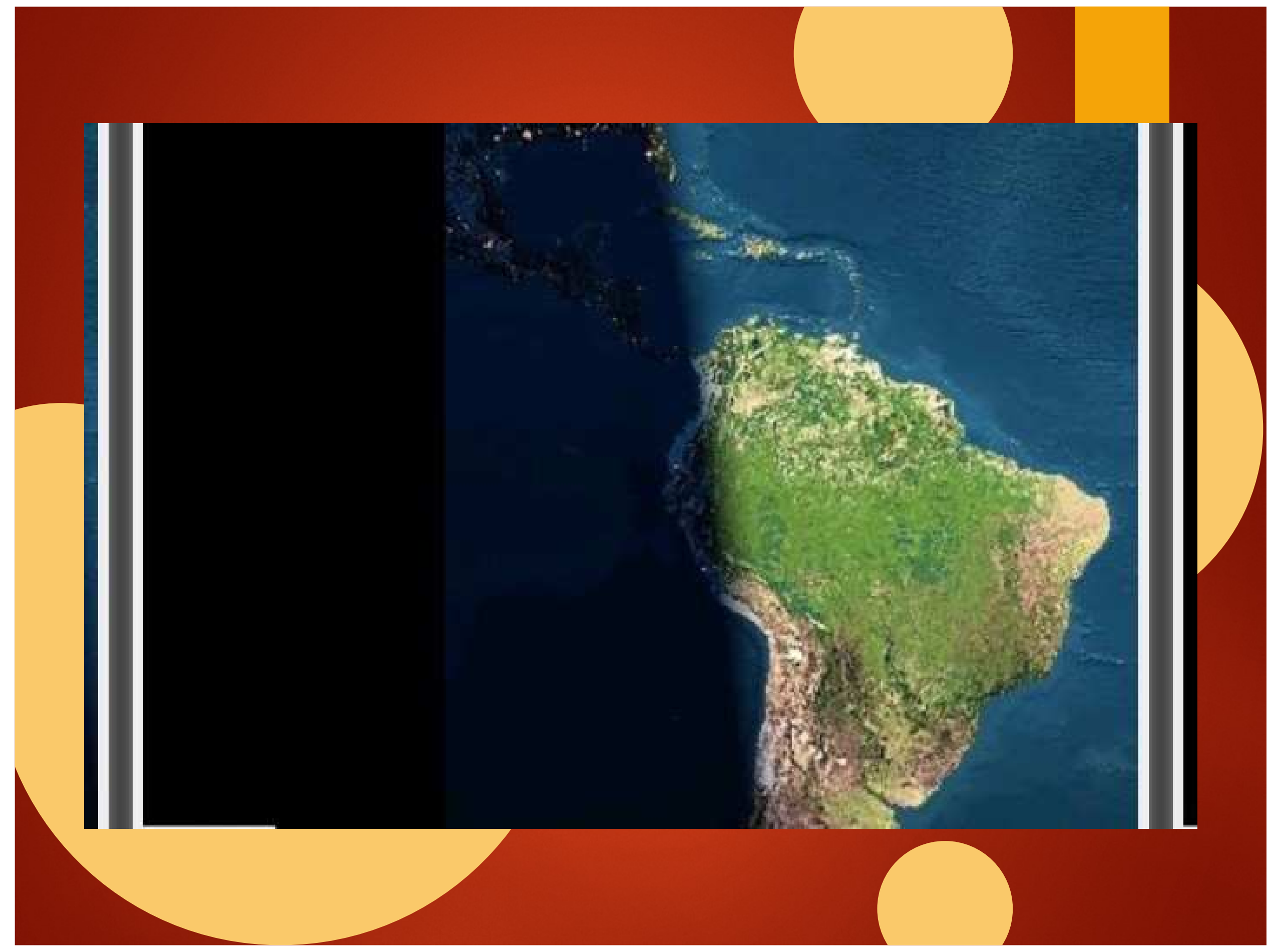




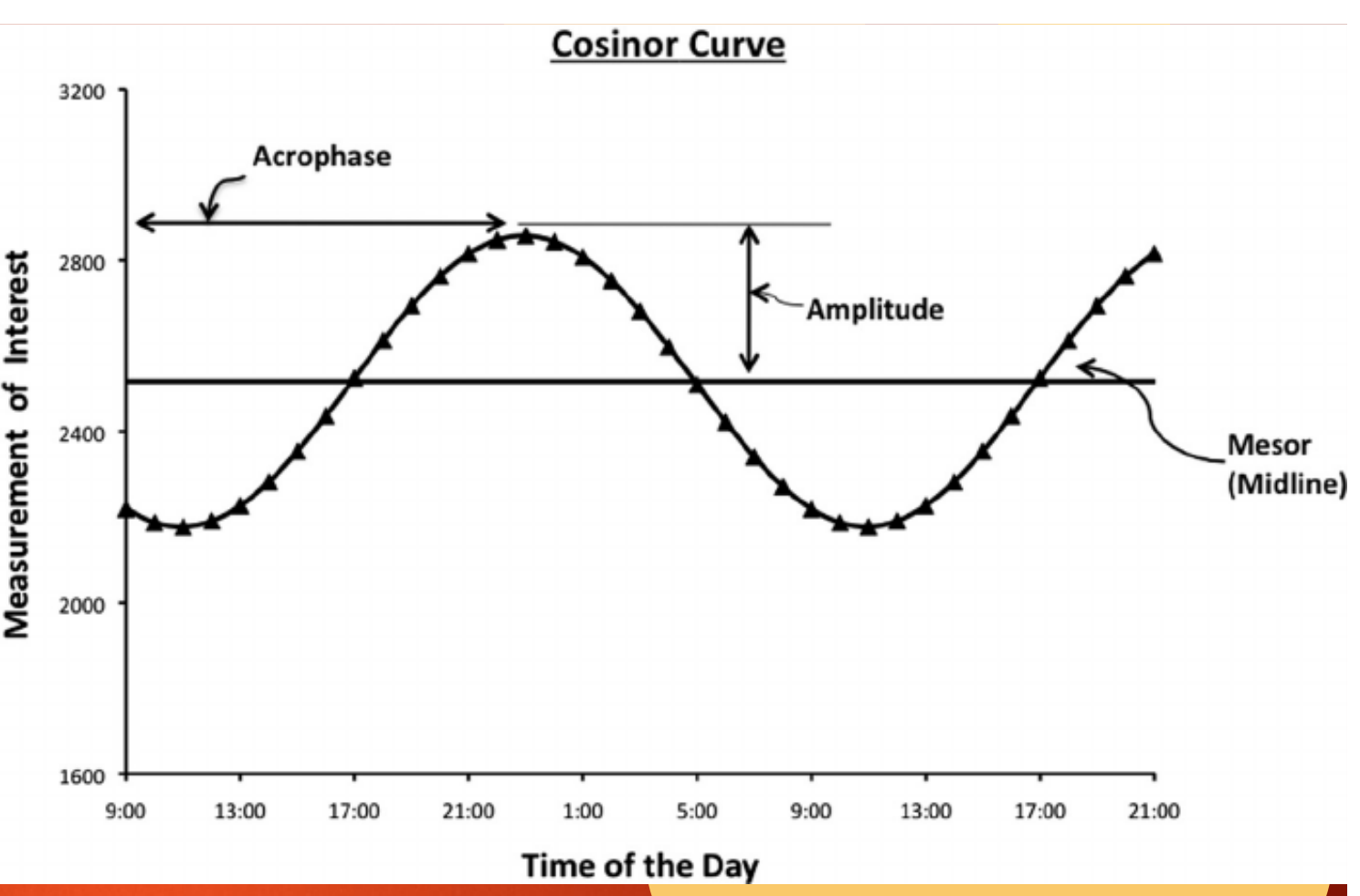

Evidence 1

Morning or evening schedules - different activities and tests in scientific areas should be taken into account as organizational concerns in order to optimize student's performance and their intelligence development. 


\section{Evidence 2}

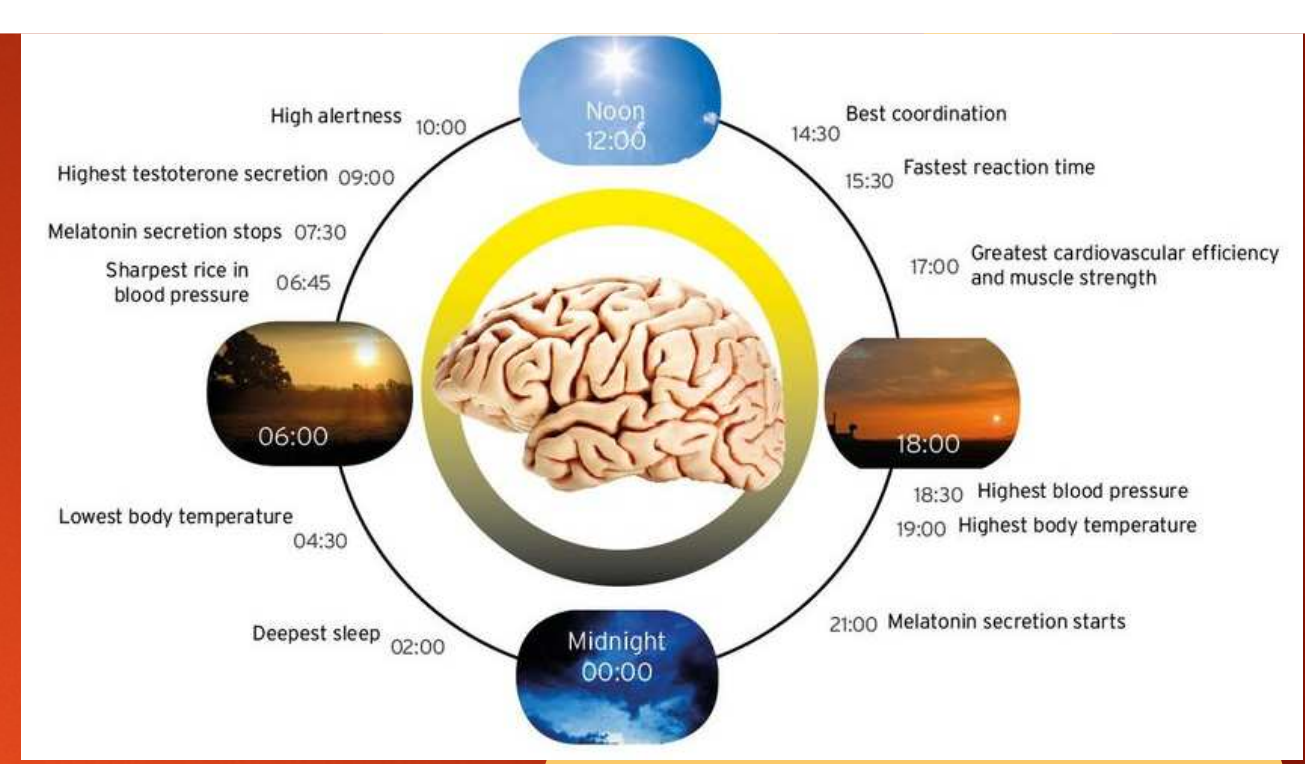

Circadian rhythms: impact the attention of children in the first school grades, attending the same timetables.

Biological clocks: individuals' preferences and the execution of specific tasks during the day in an optimal condition.

'Synchrony effect': best performance in specific time of the day but according to specific chronotypes. 
Evidence 3

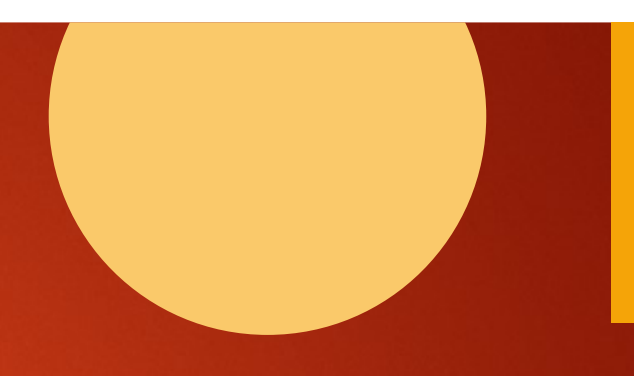

The biological predisposition - morning, intermediate or evening type - determines sleep patterns and vigil preferences - and observing disorders (deviance).

Morning individuals prefer to awake and to work earlier (vs evening types):

different performances $x$ different individuals $x$ condition = execution of the same task in the same period.

Discrepancy observed: the students with different diurnal preferences attending to the same schedules and the same testing hours. 


\section{Objective}

(part of a larger project research ongoing)

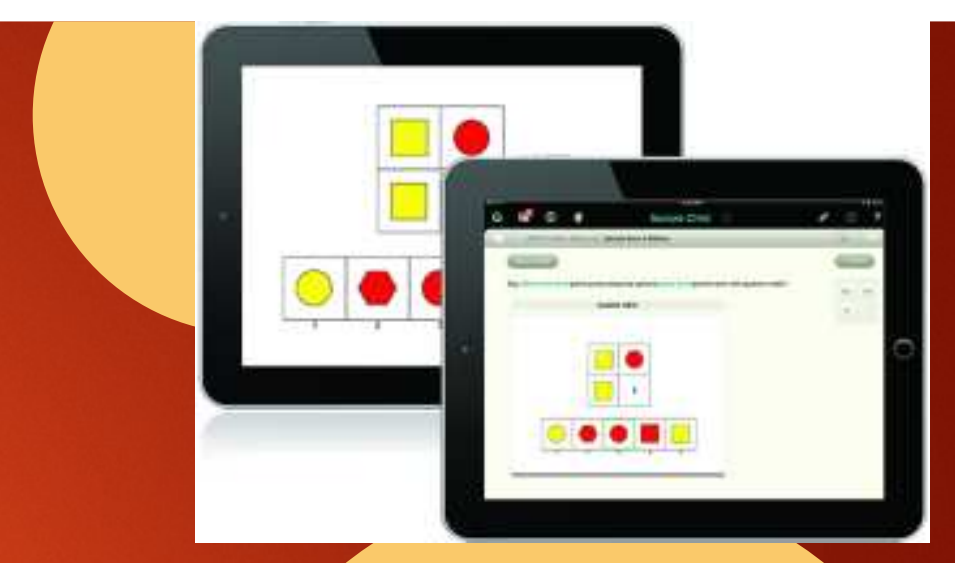

Manipulation of trial study: schedules of tasks for the same samples of children.

Goal: to understand how different chronotypes affect the performance according to the period of the day in which the test was administered.

Correlation: chronotype and cognition achievement.

Measurement: Portuguese children were evaluated concerning attention capacity - coding subscale of Wechsler intelligence scale for children-WISC-IV.

- different hours of the day and during two weeks (one-week interval). 


\section{Previous data gathered}

- The real chronotype of the children was differentty considered from the chronotype indicated by the parents, which can represent the parents' lack of knowledge about the children's need to sleep and adjust their rest and wakefulness activities.

- Children are not morning type in majority - to be revisited.

- Immigrants and natives differ for sleep schedules with implications for school success.

- Luxembourg: a case study of multicultural population immersed in the same school schedules but different home timetables - health and biology scholars should highlight factor such as the latitude.
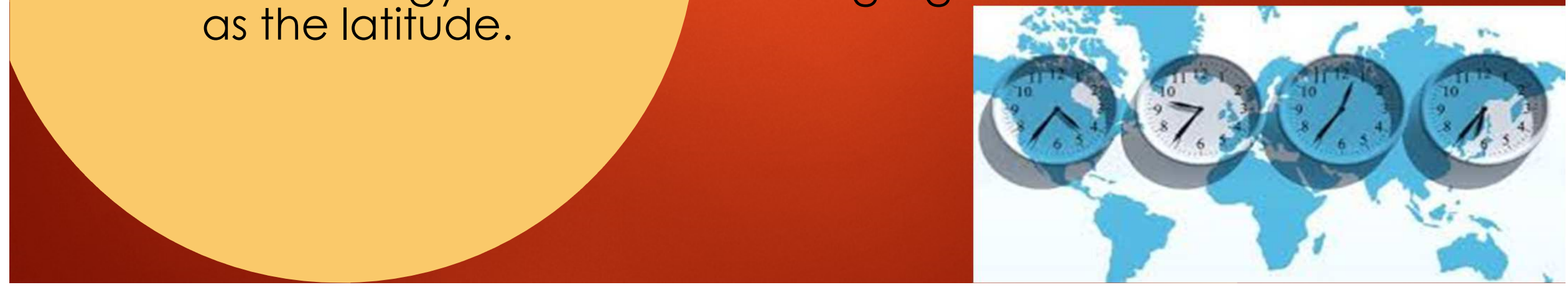


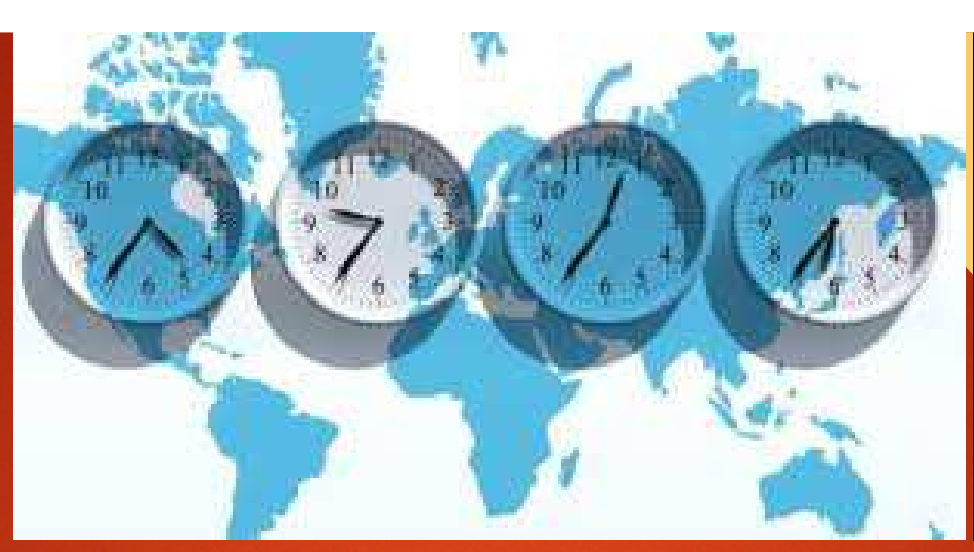

- The evidence on the variability of cut-off points may probably due to their culture and geography.

- Further studies are needed in cultural and linguistically distinct populations.

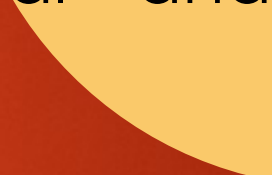

- School schedules and home activities should be revised against the timetables and the chronotype of children.
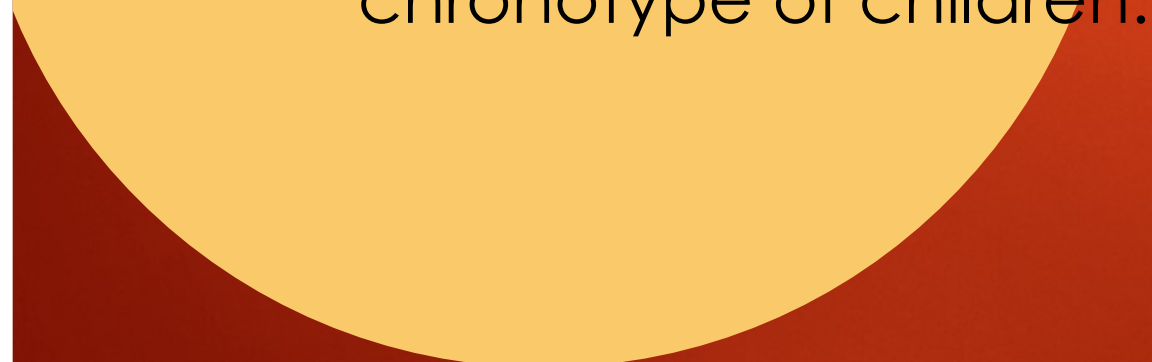


\section{Method}

\section{Participants}

- 46 school-aged children, 7 and 11 yr old, Portuguese nationality, attending the $2 \mathrm{nd}, 3 \mathrm{rd}$ and 4 th grades of Primary School.

$24(52,2 \%)$ are morning type, $22(47,8 \%)$ are evening type. The selection criteria of chronotypes followed this punctuation: extremely morning types (punctuations between $<22$ and $>36$ ), moderate morningness $(<23$ and $>26)$ and moderate eveningness $(<33$ e $>35)$. Cutoff scores were determined by percentile analysis: p 25 and $\mathrm{p} 75$.

- Considering the chronotype and the gender variable, $12(50 \%)$ morning types are males and $12(50 \%)$ morning types are females. In the same way, 11 (50\%) evening types are males and 11 (50\%) evening children are females. 


\section{Method}

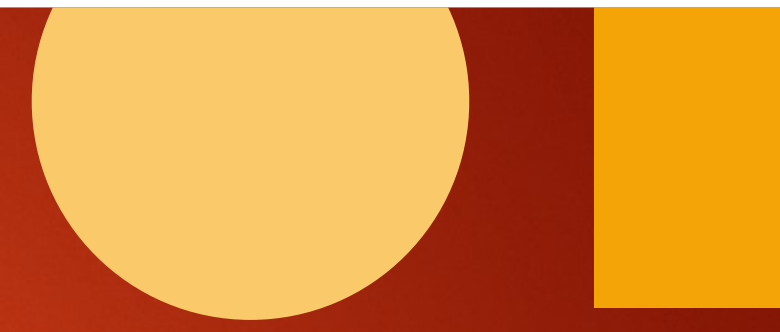

Variables and Materials

> Chronotype

- The Children's Chronotype Questionnaire - to assess the steep/vigil patterns in school days and in free days (with no school activities).

- The sleep patterns included: schedules of bedtime, sleepiness, awakeness. Based on these patterns a midsleep point was estimated and determined for each chronotype. The evening types have the tendency to experience poor sleep (less sleep duration).

- To calculate the midsleep point, it was used the formuta of Roenneberg et al. (see full paper):

[5 x (sleep period in school days) $+2 x$ (sleep period in free days) /7]. 


\section{Method}

Variables and Materials

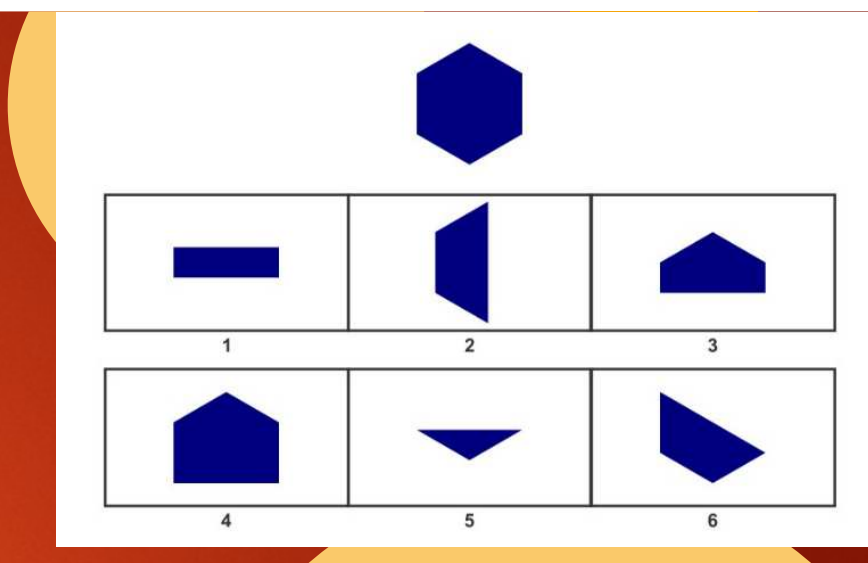

$\checkmark$ Attention

The Wechsler's coding subscale for children and adolescents (WISC - IV) was used in its Portuguese adapted version. The Portuguese test presented a cronbach' alfa between .62 and .93.

- 59 items - Code A

119 items - Code B.

The code subscale evaluates attention and processing velocity.

According to the time spent to the decoding, there are different punctuations (Table I). 


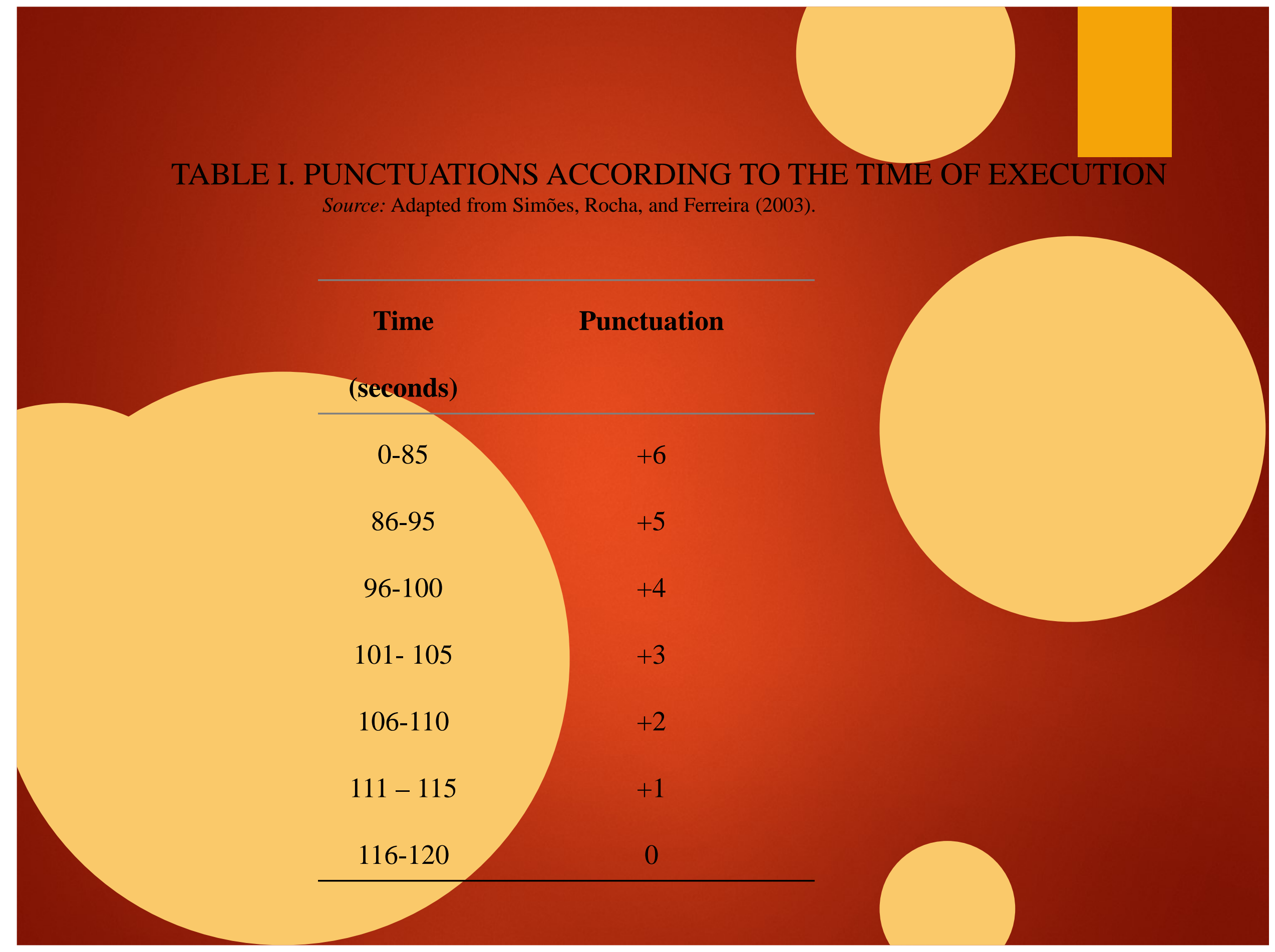




\section{Method}

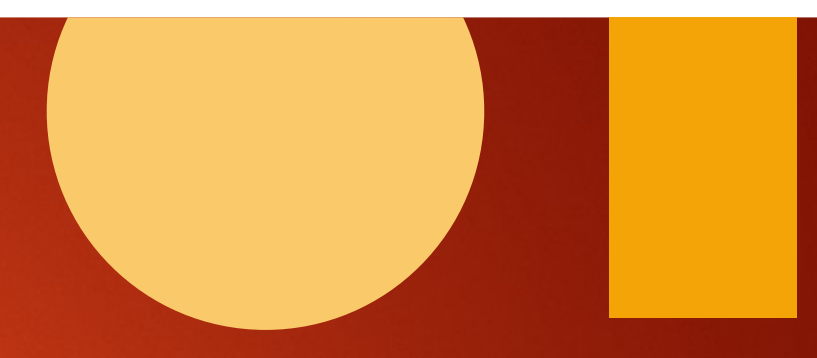

\section{Procedures}

- Samples were recruited based on school-age and absence of sleep disorders.

> The intelligence subscale was administered in two periods of the day: 9.30 am and 3.30 pm, one-week interval.

[The two sessions were established with the schools approval and with the consent of the parents. The groups were selected according to differentiated chronotypes]

Descriptive and inferential analyses were accomplished by using the SPSS, v. 24. 


\section{Results}

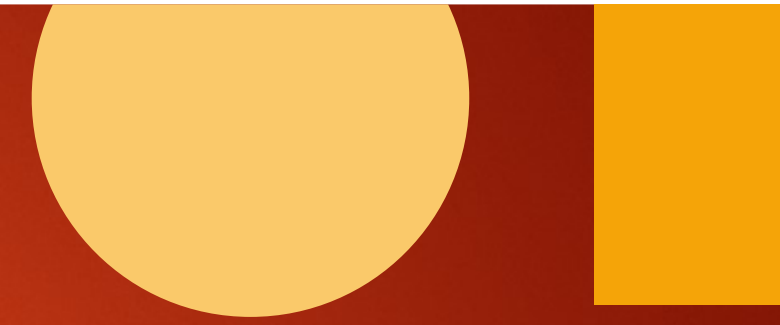

> 1. The t-Student (paired t test) revealed significant differences for the morning types in the two sessions - morning and afternoon hours: [t(23) = 2.592, $\mathrm{p}=.016]$.

> RESULT - Morning children perform better in morning session than in the afternoon session, considering the exactly same test of attention (Morning: $M=13.33, S D=2.944$; Afternoon: $M=12.13, S D=3.710$ ).

2. Considering both evaluation periods and the results for the coding subtest among the evening individuals, the paired t test demonstrated no statistical differences between the two periods of the day $[\dagger(21)=$ $.113, p=.911]$.

RESULT -The means in the two periods were very similar for the evening children.

3, The unpaired t test displayed results with significant differences in the morning session for both groups of chronotypes $[t(44)=2,604, p=.013]$, considering that the morning children showed higher means of performance $(M=13.33, S D=2.944)$ compared to the evening peers $(M=10.55, S D=4.251)$, with homogeneity variance $(F=3.113, p=.085)$.

Result - In the afternoon session, for both groups of children there were no statistical differences $[t(44)=1.376, p=.176]$ and homogeneity was showed $(F=.225, p=.638)$. 


\section{Discussion}

- The results confirm the influence of the chronotype for the intelligence, specifically referring to the attention fluctuation during the day.

More studies should examine this correlation of the chronotype with other specific cognitive skills of school-aged children considering the importance of the intelligence development at this age range.

New insight: It might be probable that the new generation of populations are changing regarding their biological clocks and eveningness is developing earlier in human being.

- Attention did not improve during the day - children tended to fail in the coding test in the afternoon period.

- Attention tasks might demand more cognitive effort associated to the afternoon period. This hypothesis may explain the approximate means of morning and evening children for the coding test, in that period (3.30 pm). 


\section{Future studies in Psycholog Biology}

- how the migration factor may explain changes in the diurnal preferences?

how the videogames frequency near the bedtime schedules may influence the cognitive performance for the after morning periods?

> how the undergraduate students may differ considering diurnal and evening university schedules, mainly observing the students who simultaneously work?

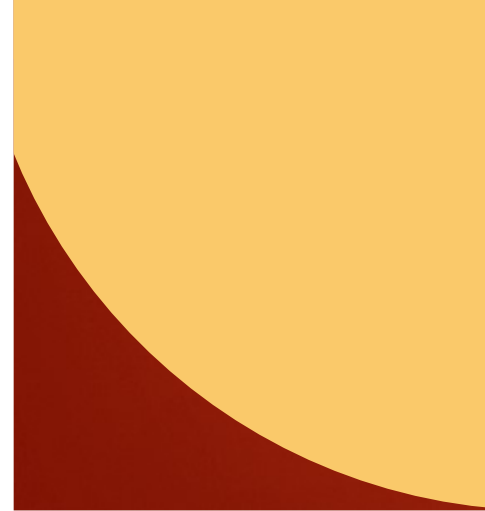




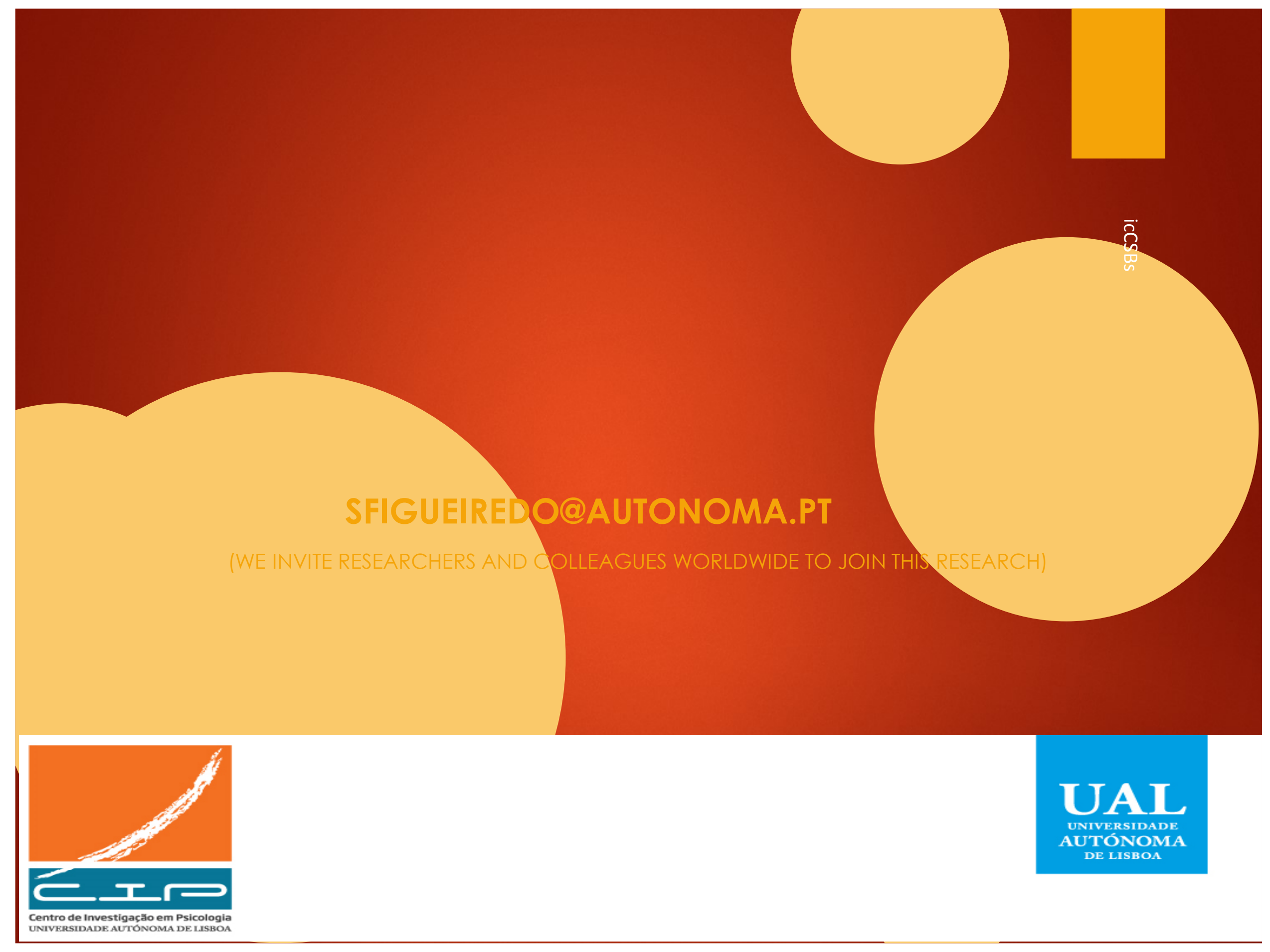

